\title{
Perencanaan ruang terbuka publik layak anak di kawasan lapangan Astina Jaya, Desa Blahbatuh, Gianyar, Bali
}

\author{
Ngakan Putu Manda Teja Putra ${ }^{1}$, Ni Wayan Febriana Utami1 ${ }^{*}$, Gusti Agung Ayu Rai Asmiwyati ${ }^{1}$ \\ 1. Prodi Arsitektur Pertamanan, Fakultas Pertanian, Universitas Udayana, Indonesia 80232 \\ *Email: wayan_febriana@unud.ac.id
}

\begin{abstract}
Planning of children-friendly open spaces in Astina Jaya, Blahbatuh Village, Blahbatuh District, Gianyar Regency, Bali. The influence of the environment determines how a child can grow in public open space which is formed as a place of development. Village conditions directly affect the protection, growth, and development of talents and interests of children, so the form of child-friendly village will support creating a decent environment for children. Astina Jaya is a public open space in Blahbatuh village which facilitates their residents to activate in outdoor space. The existence of a child-friendly open space is one indicator of the form of children friendly village. The purpose of this study was to identify and analyze the constraints and potential of the site, also to create the appropriate concept of the site development. The methods used in this research were field survey method with data collection techniques through observation, documentation, interview and distribution of questionnaire, and also by conducting literature study. Furthermore, data were processed by tabulation method and qualitative descriptive analysis method which referred to the stages of planning process. The results showed that the spatial development consists of the core area, the buffer area, and the outer area. The concept of vegetation consists of the function of microclimate control, education, and physical barrier. The concept of circulation consists of primary and secondary circulation, and the concept of child play which is developed is a children friendly open space.
\end{abstract}

Keywords: child-friendly village, child-friendly open spaces, Astina Jaya field, planning of green open space

\section{Pendahuluan}

Anak merupakan seseorang yang belum berusia delapan belas tahun, termasuk anak yang masih dalam kandungan dengan potensi dan aset yang dapat dipenuhi hak-haknya agar berkualitas dan bermanfaat bagi dirinya sendiri maupun daerahnya. Keluarga, lingkungan sekitar serta pemerintah desa merupakan pihak yang paling bertanggung jawab dalam pemenuhan hak anak. Keluarga merupakan awal mula pembentukan kepribadian anak, baik itu mengasuh, mendidik, dan melindungi anak. Selain itu, keadaan lingkungan desa juga berpengaruh langsung terhadap perlindungan, pertumbuhan, dan perkembangan bakat serta minat anak, sehingga pengembangan desa layak anak (DLA) akan berpengaruh positif dalam menciptakan lingkungan yang layak bagi anak. Kebutuhan akan ruang terbuka publik layak anak (RTPLA) menjadi salah satu indikator dalam memenuhi Desa Blahbatuh sebagai desa layak anak, sehingga pengembangan tapak dilakukan untuk memfasilitasi pengguna khususnya anak dalam beraktivitas di luar ruangan.

Penelitian ini bertujuan untuk mengidentifikasi, menganalisis potensi dan kendala serta merencanakan ruang terbuka publik layak anak di kawasan Lapangan Astina Jaya Desa Blahbatuh. Perencanaan kawasan Lapangan Astina Jaya sebagai RTPLA dilakukan dengan harapan untuk rekomendasi dan pengembangan di bidang perencanaan ruang terbuka publik yang terkonsep layak anak, fungsional, serta sesuai dengan aktivitas dan harapan pengguna, sehingga salah satu indikator dari DLA dapat terpenuhi. 


\section{Metode Penelitian}

\subsection{Waktu dan Tempat Penelitian}

Penelitian ini dilakukan selama empat bulan yaitu mulai Juli sampai Oktober 2017. Penelitian dilaksanakan di kawasan Lapangan Astina Jaya Desa Blahbatuh, Kecamatan Blahbatuh, Kabupaten Gianyar, Provinsi Bali.

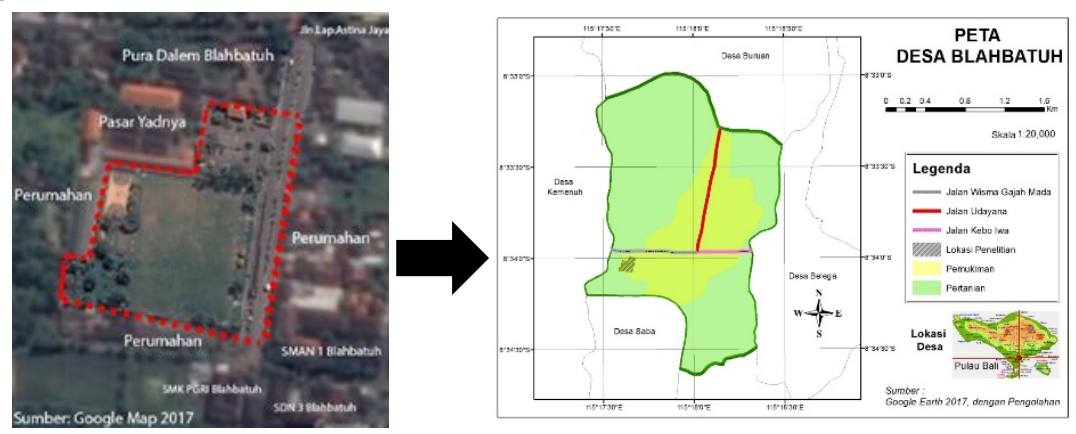

Gambar 1. Peta Desa Blahbatuh dan Lokasi Penelitian Lapangan Astina Jaya

\subsection{Alat dan Bahan Penelitian}

Alat dan bahan yang digunakan untuk melakukan penelitian antara lain alat tulis, laptop, alat ukur meteran, altimeter, kamera, perangkat lunak pengolah kata dan gambar (Microsoft Word, Google Earth Pro, ArcGIS, AutoCAD, Sketchup, Adobe Photoshop, dan Paint), lembar kuisioner dan lembar wawancara.

\subsection{Metode Penelitian}

Dalam penyusunan data, data diperoleh menggunakan metode survei lapangan dengan teknik observasi (data biofisik dan sosial), penyebaran kuisioner secara tertutup dengan responden sebanyak 30 orang (data sosial), wawancara dengan kepala desa mengenai informasi terkait obyek penelitian, dokumentasi dan studi pustaka. Dalam pengolahan data digunakan metode tabulasi, kemudian dianalisis mengikuti tahapan proses perencanaan Simonds dan Starke (2006) yaitu pemilihan tapak, inventarisasi tapak, analisis tapak, sintesis atau konseptual tapak, dan rencana tapak.

\section{Hasil dan Pembahasan}

\subsection{Kondisi Umum Desa Blahbatuh}

\subsubsection{Biofisik}

Desa Blahbatuh terletak di Kecamatan Blahbatuh, Kabupaten Gianyar. Secara geografis, Desa Blahbatuh berada pada ketinggian kurang lebih $80 \mathrm{~m}$ dpl dengan bentuk permukaan tanah atau bentang lahan yang relatif datar dan merupakan dataran rendah. Desa Blahbatuh terdiri dari 12 dusun dengan batas wilayah di sebelah utara yaitu Desa Buruan, di sebelah selatan yaitu Desa Saba, di sebelah barat yaitu Desa Kemenuh, dan sebelah timur yaitu Desa Belega. Luas wilayah Desa Blahbatuh yaitu $4,67 \mathrm{~km}^{2}$ dan luas lapangan Astina Jaya yaitu $0,019 \mathrm{~km}^{2}$ atau sebesar $0,40 \%$ dari total luas wilayah desa. Saat ini, penggunaan lapangan Astina Jaya sebagai ruang publik di kota untuk kegiatan seperti pekan olahraga dan seni pelajar Kabupaten Gianyar dan pekan olahraga Desa Blahbatuh.

\subsubsection{Sosial}

Jumlah Penduduk di Desa Blahbatuh pada tahun 2016 sebanyak 10.599 jiwa yang terdiri dari laki - laki sebanyak 5.290 jiwa dan perempuan sebanyak 5.310 jiwa, dengan jumlah anak sebanyak 2.544 jiwa atau sebesar $24 \%$ dari total jumlah penduduk Desa Blahbatuh. Desa Blahbatuh memiliki satu puskesmas di bidang kesehatan, instansi pendidikan mulai dari TK sampai dengan SMA/SMK (BPS Kab. Gianyar, 2016). Dalam pemenuhan Desa Blahbatuh sebagai DLA diacu dari Peraturan Menteri PPPA RI yang dikelompokan lima indikator yaitu hak sipil dan kebebasan, kesehatan, lingkungan keluarga, pendidikan, pemanfaatan waktu luang dan kegiatan rekreasi. RTPLA menjadi nilai tambah dari segi pemanfaatan waktu luang dan kegiatan rekreasi untuk menunjang aktivitas pengguna khususnya anak. 


\subsection{Kondisi Lapangan Astina Jaya \\ 3.2.1 Aspek biofisik}

Kawasan Lapangan Astina Jaya memiliki luas $19.000 \mathrm{~m}^{2}$ dengan batas sebelah utara terdapat Pura Dalem Desa Blahbatuh, sebelah timur terdapat Jalan Lapangan Astina Jaya Blahbatuh, sebelah selatan terdapat satu rumah penduduk serta kawasan instansi pendidikan, dan sebelah barat terdapat satu rumah penduduk. Secara umum, wilayah Desa Blahbatuh memiliki bentuk permukaan tanah yang relatif datar dan merupakan dataran rendah dengan ketinggian wilayah $80 \mathrm{~m}$ dpl (BLH Kab. Gianyar, 2016).Tapak diakses melalui Jalan Raya Wisma Gajah Mada Blahbatuh menuju Jalan Lapangan Astina Jaya Blahbatuh untuk arah utara dan barat. Akses lain menuju tapak dengan melalui Jalan Serma Darya menuju Jalan Kapten Japa untuk arah timur dan selatan. Kondisi IKlim pada saat pengambilan data pada Februari 2018 dengan rata-rata suhu sebesar $24.8^{\circ} \mathrm{C}$ dan kelembaban udara rata-rata $79.50 \%$. Curah hujan rata-rata dalam setahun sebesar 11.519 $\mathrm{mm} /$ tahun, serta kecepatan angin rata-rata adalah 7 sampai $27 \mathrm{~km} / \mathrm{jam}$. Fasilitas eksisting yang terdapat pada tapak adalah parkir area, gazebo, pedestrian track, jogging track, lapangan sepak bola, lapangan basket, open stage, tugu pahlawan, toilet, serta beberapa utilitas seperti lampu taman, penerangan jalan utama (PJU), sumber air, sumber listrik, dan saluran drainase.

Good view pada kawasan Lapangan Astina Jaya terletak pada area penerimaan (welcome area), sedangkan visual yang kurang baik (bad view) tampak pada area yang terletak di sebelah barat yaitu area tugu pahlawan dan toilet. Area tersebut ditumbuhi oleh rumput liar, tidak terawatnya toilet dan banyak terdapat sampah di dalam tapak. Vegetasi eksisting yang terdapat pada tapak yaitu kamboja (Plumeria Sp.), sawo kecik (Manilkara kauki), ketapang (Terminalia catappa), kelapa (Cocos nucifera), mangga (Mangifera indica), cempaka (Magnolia champaca), beringin (Ficus benjamina), bodhi (Ficus rumphi), kasia (Cassia surattensis), spatodea (Spathodea campanulata), srikaya (Annona squamosa), rowalea (Ruellia brittoniana), palem ekor tupai (Wodyetia bifurcate), spider lily (Hymenocallis), hanjuang (Cordyline fruticosa), kembang sepatu (Hibiscus rosa), waregu (Rhapis excelca), puring (Codiaeum variegatum), lidah mertua (Sansevieria).

\subsubsection{Aspek sosial}

Kawasan Lapangan Astina Jaya awalnya difasilitasi untuk penduduk Desa Blahbatuh untuk beraktivitas di luar ruangan dan kini penduduk luar desa ikut memanfaatkan fasilitas yang ada. Waktu aktivitas pada tapak sebagian besar pada sore hari dengan pengguna dominan anak-anak. Untuk saat ini aktivitas yang dilakukan pada tapak seperti berjalan-jalan, bersantai, bermain dan berolahraga. Ruang personal adalah ruang yang mengelilingi setiap orang atau area yang dianggap sebagai teritori atau zona nyaman seseorang (Hall, 1966). Jarak antar pribadi manusia yang digunakan yaitu jarak sosial sebagai daya dukung pengunjung dalam berinteraksi dalam tapak dengan perhitungan jarak sosial rentang 1,2 m sampai 2,1 m. Adapun keinginan pengguna dalam pengembangan tapak diketahui melalui hasil kuisioner dengan 30 responden yang menggunakan tapak dilihat dari Gambar 2.

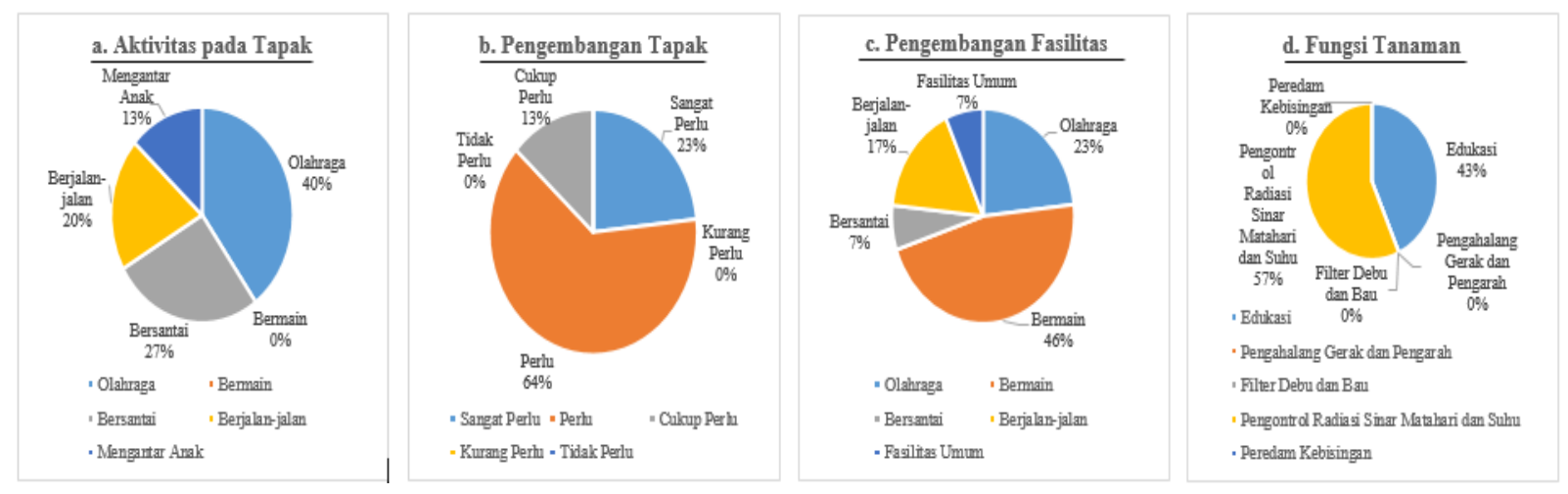

Gambar 2. Beberapa Hasil Kuesioner terhadap Pengguna Tapak 


\subsection{Analisis dan Sintesis \\ 3.3.1 Aspek Biofisik}

Kawasan Lapangan Astina Jaya merupakan taman kelurahan yang dikaitkan dengan penyediaan ruang terbuka hijau publik melalui Peraturan Menteri PU No.5 Tahun 2008 memiliki luas minimal/unit $9.000 \mathrm{~m}^{2}$ dengan unit lingkungan sebanyak 30.000 jiwa (Kementrian PU, 2008). Jika dikaitkan dengan luas tapak maka lapangan mampu mengakomodasi seluruh penduduk Desa Blahbatuh seperti tercantum pada kriteria RTH taman kelurahan. Dari segi kemudahan, lokasi tapak strategis dilihat dari lokasi tapak berada pada pusat lingkungan dan dapat ditempuh dari berbagai jalan permukiman. Dari segi keselamatan dan keamanan, tapak berada pada kawasan dekat permukiman dan tidak terpencil, sehingga terjangkau dalam jarak pandang pengawasan penduduk. Lokasi tidak dekat dengan jalur jalan raya utama desa, sehingga anak tidak terganggu dalam melakukan aktivitas pada tapak seperti terjadi kecelakaan, polusi, dan kebisingan. Kawasan tapak terdapat sub jalan dari jalan utama yang juga dilalui oleh kendaraan, maka perlu adanya pembatas di sekeliling tapak untuk meningkatkan keselamatan dan kenyamanan tapak khususnya bagi anak.

Keadaan topografi yang datar merupakan potensi area terbangun yang menunjang berbagai aktivitas pasif dan aktif. Pola sirkulasi pada tapak adalah linear dan bersifat mengarahkan pengunjung untuk masuk ke dalam tapak. Aksesibilitas menuju tapak mudah diakses dan jalan dalam kondisi baik, namun sirkulasi dalam tapak tidak sesuai dengan fungsinya, kendaraan dapat masuk ke areal aktivitas pengguna dan belum adanya pembagian ruang sirkulasi, sehingga dapat direncanakan ruang sirkulasi yang ramah bagi pengguna khususnya anak. Hasil indeks kenyamanan thermal tapak sebesar $24,39^{\circ} \mathrm{C}$ masuk ke dalam kriteria nyaman.

Fasilitas yang terdapat pada tapak cukup minim untuk memenuhi kebutuhan anak dalam beraktivitas di luar ruangan. Belum terdapatnya konsep permainan anak yang diterapkan pada tapak, maka diperlukan penerapan konsep permainan anak yang dapat menunjang aktivitas anak. Perlu ditambahkan beberapa permainan yang rekreatif dan edukatif, sehingga permainan yang dihadirkan dapat mengajak anak saling berinteraksi dengan sesama maupun dengan lingkungan. Permainan anak toodler dikombinasikan dengan alas berbahan karet, rumput, maupun pasir untuk memberi rasa nyaman pada anak (Baskara, 2011) dan mengurangi penggunaan perkerasan pada ruang terbuka publik untuk menunjang hijauan tapak. Fasilitas parkir yang tidak digunakan dengan baik, sehingga pembatas tapak perlu dikendalikan agar kendaraan tidak memasuki area aktivitas. Banyak timbunan sampah tidak pada tempatnya, sehingga jumlah tempat sampah ditambah dan penambahan volume tempat sampah pada area luar agar pembuangan sampah sementara dipusatkan pada satu tempat. Kondisi toilet yang tidak baik perlu ditata kembali. Terdapat area tugu pahlawan yang tidak terawat dan area kosong yang belum dikembangkan. Tugu pahlawan dikembangkan sebagai landmark dan media edukasi dan ditata agar pada area tersebut pengunjung dapat beraktivitas pada area tugu pahlawan. Area kosong di sekitar tugu pahlawan dikembangkan sebagai area bermain anak dan ditata dengan baik.

Good view terdapat pada welcome area dan parkir area. Bad view pada tapak dapat berpotensi sebagai good view pada pengembangan area tugu pahlawan, timbunan sampah yang telah dikendalikan, dan area aktivitas pengguna. Dengan kondisi tanaman yang ada pada tapak, maka diperlukan pemilihan tanaman yang tepat agar dapat tumbuh optimal dan sesuai dengan fungsinya. Beberapa vegetasi yang dipertahankan karena tumbuh baik dan memberi keteduhan pada tapak seperti ketapang (Terminalia catappa), kasia (Cassia surattensis), dan bodhi atau ancak (Ficus rumphii). Pohon bodhi atau ancak (Ficus rumphii) memiliki filosofi sebagai tempat Sang Buddha Gautama bersemedi dan memperoleh pencerahan. Pohon ini dipandang suci oleh penganut agama Hindu, Buddha (Wikipedia, 2017). Pohon tersebut dapat difungsikan sebagai tanaman khas pada tapak, karena pohon bodhi merepresentasikan keberadaan Wihara Amurtha Bhumi yang terdapat di Desa Blahbatuh, sehingga dapat dilestarikan dan mengedukasi pada tapak.

\subsubsection{Aspek sosial}

Adanya minat penduduk khususnya anak dalam beraktivitas di luar ruangan dengan memanfaatkan Lapangan Astina Jaya sebagai ruangnya, sehingga diterapkan pengembangan ruang dan fasilitas pengguna khususnya anak. Keikutsertaan orang tua dalam melakukan aktivitas bersama anak pada tapak, sehingga dapat menjalin hubungan baik anak dan orang tua melalui indikator pengawasan, keramahtamahan, rasa percaya, dan tanggung jawab khususnya untuk berekreasi bersama (Budyatna \& Ganiem, 2011). Selain itu, kawasan Lapangan Astina Jaya dekat dengan instansi pendidikan, sehingga tapak dapat dimanfaatkan 
sebagai fasilitas pendidikan olahraga. Melalui RTPLA di kawasan Lapangan Astina Jaya diharapkan dapat menumbuhkan keinginan beraktivitas di luar ruangan, sehingga anak menjadi peduli terhadap lingkungan sekitar, anak menjadi atraktif, kreatif, dan edukatif. Sesuai dengan indikator DLA yang mewadahi kegiatan rekreasi dan pemanfaatan waktu luang, dimana anak berhak beristirahat, bersantai, dan bermain.

\section{$3.4 \quad$ Konsep \\ 3.4.1 Konsep dasar}

Konsep dasar dari kawasan Lapangan Astina Jaya ini adalah ruang terbuka publik layak anak dalam bentuk taman lingkungan untuk umum dan secara khusus untuk anak dalam batas usia 3-18 tahun, yang dapat menjadi sarana rekreasi yang atraktif dan edukatif yang bertujuan untuk menstimulasi beragam kecerdasan anak di lingkungan tempat tinggal. Usia tersebut menyesuaikan dengan kesiapan anak beraktivitas di luar ruangan yang dimulai dari usia pra-sekolah.

\subsubsection{Konsep pengembangan}

\subsubsection{Konsep ruang}

Adapun konsep ruang yang direncanakan pada tapak yaitu ruang inti, ruang penyangga, dan ruang luar. Keterkaitan ruang, daya dukung, aktivitas, dan fasilitas dapat dilihat pada (Tabel 1).

Tabel 1. Keterhubungan Ruang, Daya Dukung, Aktivitas, dan Fasilitas dalam RTPLA

\begin{tabular}{|c|c|c|c|c|}
\hline Ruang & $\begin{array}{l}\text { Selang } \\
\text { Usia }\end{array}$ & $\begin{array}{c}\text { Selang Daya } \\
\text { Dukung (orang) }\end{array}$ & Aktivitas & Fasilitas \\
\hline $\begin{array}{c}\text { Inti } \\
13 \% \\
\left(2.500 \mathrm{~m}^{2}\right)\end{array}$ & $\begin{array}{l}3-12 \\
\text { tahun }\end{array}$ & $\begin{array}{l}555(1,2 \mathrm{~m})- \\
180(2,1 \mathrm{~m})\end{array}$ & $\begin{array}{l}\text { 1. Bermain } \\
\text { permainan fisik, } \\
\text { 2. Bersantai, } \\
\text { Bersosialisasi, dan } \\
\text { pendamping } \\
\text { mengawasi anak } \\
\text { 3. Bersepeda } \\
\text { 4. Mengunjungi tugu } \\
\text { pahlawan dan } \\
\text { edukasi non formal }\end{array}$ & $\begin{array}{l}\text { 1. Permainan anak ( jungkat-jungkit, ayunan, seluncuran, } \\
\text { mangkok putar, bak pasir, atraktif dinamika topografi, } \\
\text { dan kombinasi set permainan fisik ). } \\
\text { 2. Bangku taman, lahan rumput, tanaman peneduh, } \\
\text { tanaman pembatas fisik. } \\
\text { 3. Jalan setapak, tempat parkir sepeda. } \\
\text { 4. Tugu Pahlawan Serma Darya, tanaman obat dan } \\
\text { buah, boardwalk, papan interpretasi, papan nama } \\
\text { tanaman. } \\
\text { 5. Toilet, Open stage, lampu taman, tempat sampah. }\end{array}$ \\
\hline $\begin{array}{c}\text { Penyangga } \\
58 \% \\
\left(11.000 \mathrm{~m}^{2}\right)\end{array}$ & $\begin{array}{l}\text { 6-18 } \\
\text { tahun }\end{array}$ & $\begin{array}{l}2.444(1,2 \mathrm{~m})- \\
793(2,1 \mathrm{~m})\end{array}$ & $\begin{array}{l}\text { 1. Berolahraga } \\
\text { 2. Bersepeda } \\
\text { 3. Berjalan-jalan } \\
\text { 4. Beristirahat }\end{array}$ & $\begin{array}{l}\text { 1. Lapangan sepak bola, lapangan basket, jogging track, } \\
\text { gym outdoor. } \\
\text { 2. Jalur sepeda } \\
\text { 3. Jalan setapak, batu refleksi } \\
\text { 4. Gazebo, lahan rumput, tanaman peneduh } \\
\text { 5. Lampu taman, tempat sampah, tanaman pembatas } \\
\text { fisik. }\end{array}$ \\
\hline $\begin{array}{c}\text { Luar } \\
29 \% \\
\left(5.500 \mathrm{~m}^{2}\right)\end{array}$ & $\begin{array}{l}\text { Segala } \\
\text { Usia }\end{array}$ & $\begin{array}{l}1.222(1,2 \mathrm{~m})- \\
396(2,1 \mathrm{~m})\end{array}$ & $\begin{array}{ll}\text { 1. } & \text { Memarkir } \\
\text { kendaraan } \\
\text { 2. Memasuki } \\
\text { Lapangan Astina } \\
\text { Jaya } \\
\text { 3. Bersantai dan } \\
\text { berisirahat } \\
\text { 4. Menikmati } \\
\text { pemandangan }\end{array}$ & $\begin{array}{l}\text { 1. Tempat parkir kendaraan, tanaman peneduh } \\
\text { 2. Pintu gerbang (entrance), signage } \\
\text { 3. Balai, gazebo } \\
\text { 4. Jalur pedestrian, lampu taman, tempat pembuangan } \\
\text { sampah sementara, tanaman pembatas fisik. }\end{array}$ \\
\hline
\end{tabular}

Tata letak taman bermain anak didasari zonasi aktivitas bermain aktif-pasif, kelompok umur, dan jenis permainan (Gambar 3). Pemisahan diperlukan untuk memastikan tidak saling terganggunya antar kegiatan bermain (Baskara, 2011). Anak usia di bawah tiga tahun masih sulit untuk berbagi dan tidak banyak bicara satu sama lain, serta terkadang mereka masih takut untuk bertemu orang baru, sehingga direncanakan mulai usia tiga tahun yang sudah mampu beradaptasi, memiliki kemampuan emosi dan sosial. 


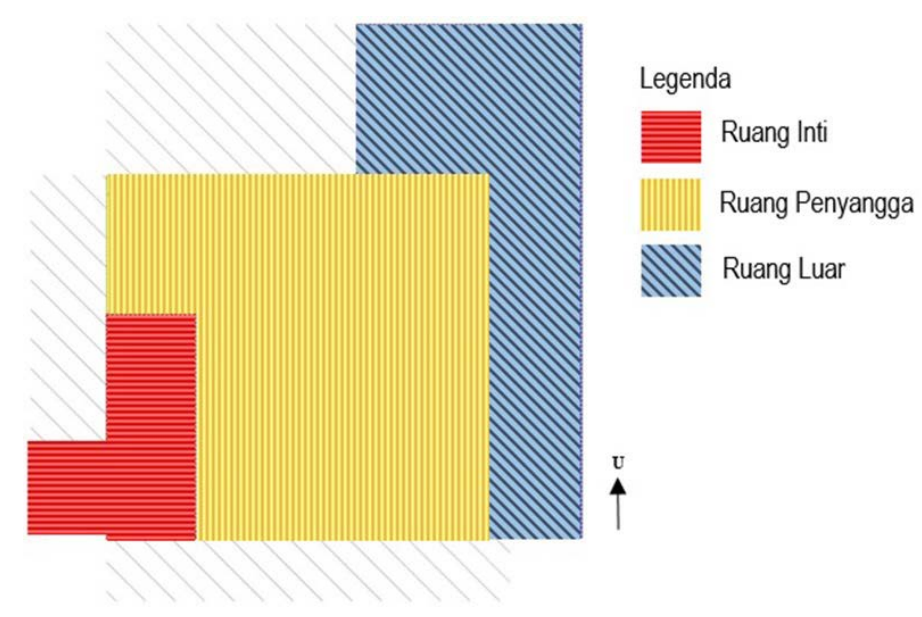

Gambar 3. Konsep Pengembangan Ruang

\subsubsection{Konsep permainan anak}

Konsep permainan anak menekankan pada usaha menstimulasi kecerdasan anak secara komprehensif (motorik, sosial, interpersonal, dII). Hal ini diwujudkan dengan menghadirkan fasilitas seperti permainan fisik yang menuntut anak selalu bergerak (permainan jungkat-jungkit, ayunan, seluncuran, mangkok putar, atraktif dinamika topografi, dan kombinasi set permainan fisik), permainan sosial yang menitikberatkan pada sosial serta hubungan antar pemain (bermain sepak bola, basket, bersepeda, kejar-kejaran, maupun bersembunyi) dan permainan kreatif yang membutuhkan imajinasi dan khayalan. Selain itu, permainan dalam ketenangan dihadirkan dengan penyediaan untuk beristirahat dan berpikir dalam taman bermain. Dengan memberi suasana tenang membuat anak dapat berkonsenterasi dengan aktivitasnya, bebas dari gangguan luar dengan penerapan kotak pasir, meja dan kursi, serta area yang memiliki pembatas fisik dan cukup terlindungi dari sengatan matahari.

\subsubsection{Konsep edukasi}

Edukasi mengenai lingkungan (kecerdasan naturalis) merupakan konsep yang dihadirkan agar anak dapat lebih peduli terhadap lingkungan yang ada di sekitarnya yang dimulai dari taman lingkungan. Konsep ini didukung oleh ruang inti dengan menghadirkan tanaman obat dan buah beserta fasilitas papan namanya, sehingga pengunjung khususnya anak dapat bermain dan menambah pengetahuannya mengenai jenis-jenis tanaman yang ada di sekitarnya melalui aktivitas mengamati, melihat, dan merasakan. Selain itu, area tugu pahlawan juga dikembangkan sebagai fasilitas edukasi sebagai kepedulian terhadap jasa pahlawan dan dijadikan landmark dengan penambahan papan interpretasi tugu dan membuka pandangan tugu pahlawan agar terlihat dari ruang luar.

\subsubsection{Konsep vegetasi}

Vegetasi yang direncanakan sebagai pengembangan Lapangan Astina Jaya adalah vegetasi dengan fungsi pembatas fisik, fungsi pengendali iklim dan fungsi edukasi (Gambar 4). Fungsi tanaman sebagai pembatas fisik dapat memberi kesan ruang, hal ini dilakukan untuk membedakan ruang dan membatasi aktivitas yang berada pada ruang aktif maupun pasif. Bentuk fisik tanaman memiliki tajuk rapat, tingginya tidak melebihi tinggi manusia, dan lebih diutamakan penggunaan jenis tanaman yang tidak berduri agar aman bagi anak. Fungsi tanaman sebagai pengendali iklim dapat mengontrol radiasi sinar matahari dan suhu pada tapak. Tanaman mampu menyerap panas dari pancaran sinar matahari dan memantulkannya sehingga menimbulkan keteduhan dan penurunan suhu iklim mikro (Hakim dan Utomo, 2008). Pohon ditata dan dapat sebagai sarana bermain anak untuk dipanjat, bergantung atau dengan membuat fasilitas permainan untuk menstimulasi kecerdasan motorik anak. Tanaman yang dikonsepkan untuk mendukung fungsi edukasi lingkungan pada tapak ruang inti adalah jenis tanaman obat dan buah yang dapat dimanfaatkan oleh pengguna tapak, kemudian tanaman ini akan diberikan papan nama tanaman. Selain memiliki fungsi edukasi, tanaman yang dikonsepkan juga memberikan fungsi pelestarian alam, penghijauan, dan keindahan, sehingga dapat diterapkan pada ruang terbuka publik. Konsep ruang inti dengan menggunakan tanaman yang dapat memberikan manfaat seperti 
tanaman obat dan tanaman buah diharapkan dapat meningkatkan pengetahuan pengguna khususnya anak terhadap jenis-jenis tanaman yang ada disekitarnya dan manfaatnya, sehingga anak dapat bermain dan belajar pada ruang inti.

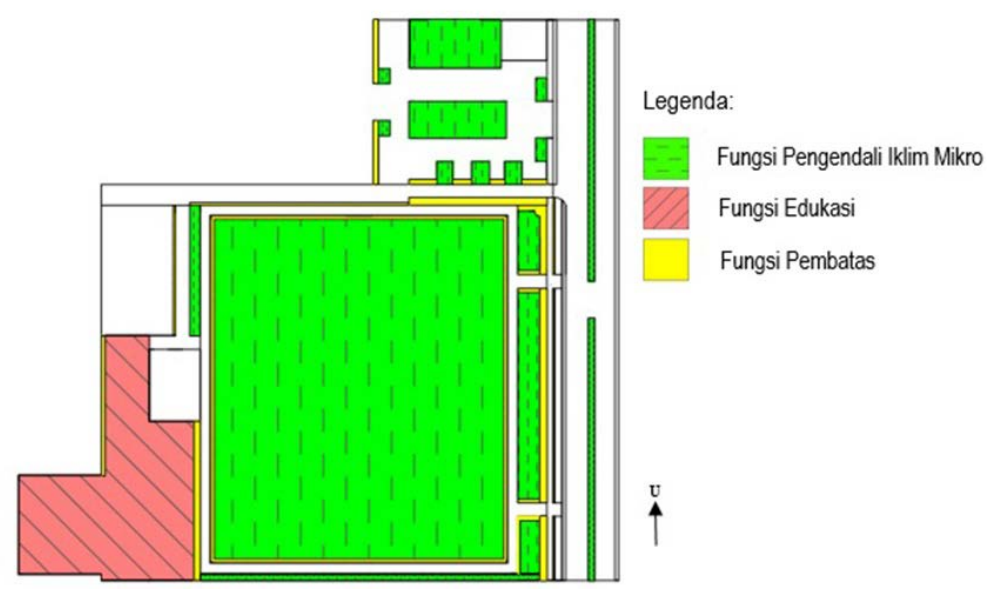

Gambar 4. Konsep Pengembangan Vegetasi

\subsubsection{Konsep sirkulasi}

Pengembangan sirkulasi dilakukan berdasarkan kondisi fisik, sehingga sistem sirkulasi sangat erat hubungannya dengan pola penempatan aktivitas dan pola penggunaan lahan sehingga sirkulasi merupakan penggerak dari ruang yang satu ke ruang yang lain (Hakim dan Utomo, 2008). Sirkulasi pada tapak dibagi menjadi dua yaitu sirkulasi primer yang menghubungkan jalan utama dengan tapak dan sirkulasi sekunder menghubungkan sirkulasi primer tapak dengan antar ruang di dalam tapak (Gambar 5).

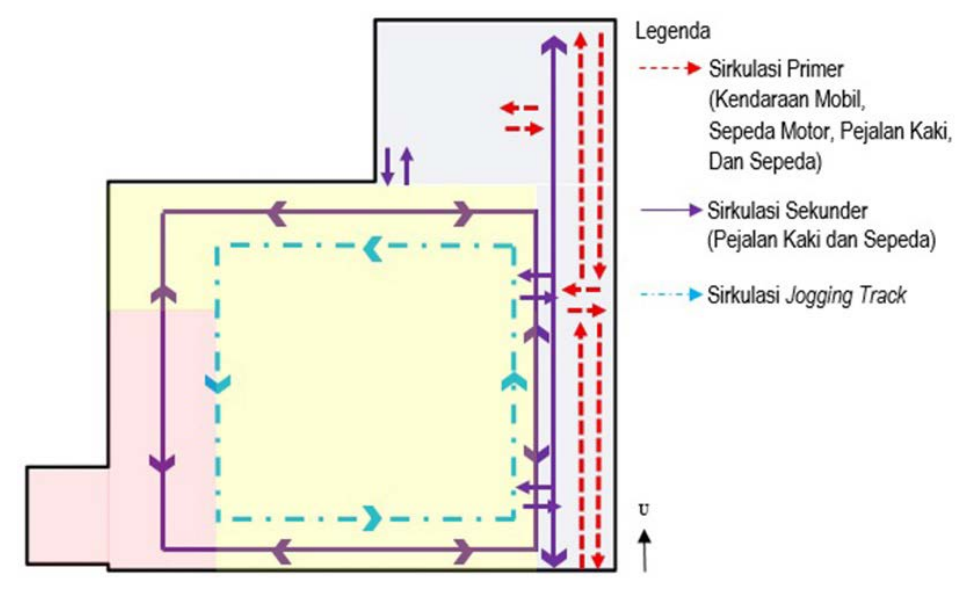

Gambar 5. Konsep Pengembangan Sirkulasi

\subsection{Perencanaan}

Konsep rencana ruang, rencana sirkulasi, dan rencana vegetasi yang telah dijabarkan selanjutnya digambarkan dalam bentuk rencana tapak (site plan) yang dapat dilihat pada Gambar 6 yang merupakan produk penerjemah konsep perencanaan ruang terbuka publik layak anak dalam bentuk gambar, serta merupakan pendetailan dari konsep ruang. 


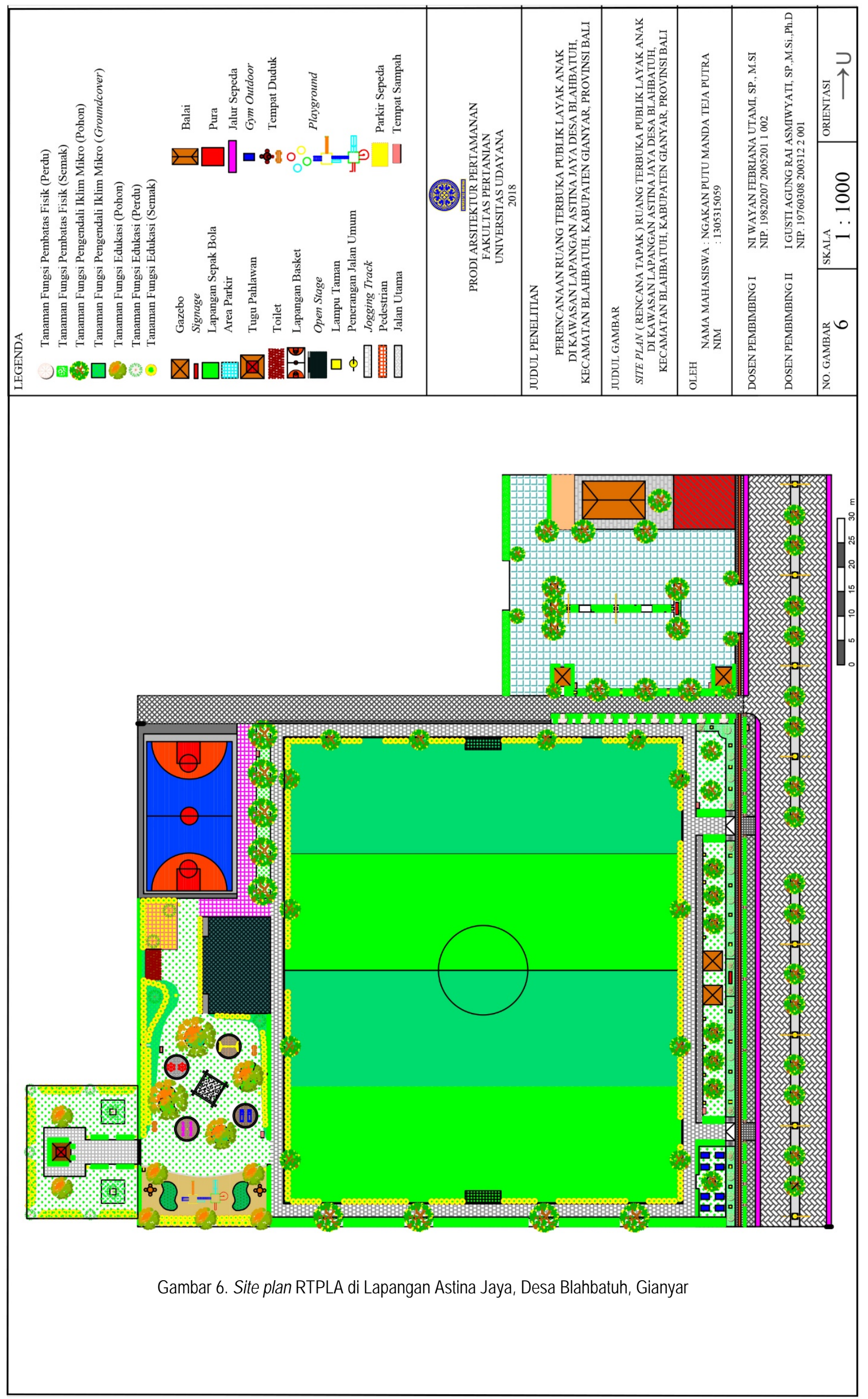



pada (Gambar 7).

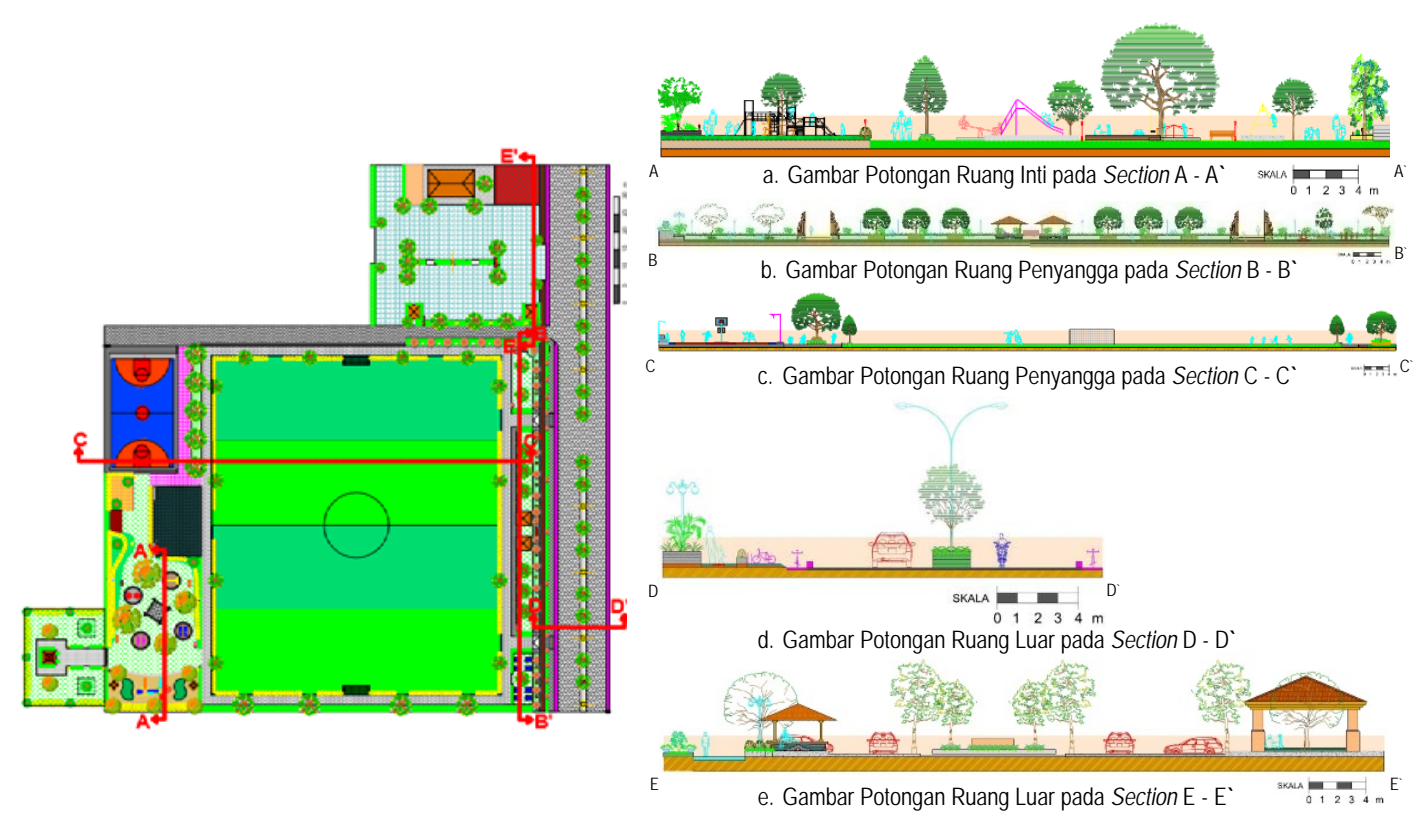

Gambar 7. Section pada Site Plan Lapangan Astina Jaya

Ruang inti terdapat fasilitas yang terkonsep bagi pengguna berusia 3 - 12 tahun dengan luas area $2.500 \mathrm{~m}^{2}$. Ruang inti mengakomodasi fasilitas edukatif dan atraktif melalui bermain permainan fisik, sosial, dan kreatif (jungkat-jungkit, ayunan, seluncuran, mangkok putar, bak pasir, atraktif dinamika topografi, dan kombinasi set permainan fisik) (Gambar 8a), bersepeda, bersantai, bersosialisasi, pendamping mengawasi anak, mengunjungi tugu pahlawan dan edukasi non formal. Fungsi tanaman pengendali iklim mikro, fungsi pembatas fisik, dan fungsi tanaman edukasi diterapkan untuk menunjang konsep edukasi dan hijauan pada ruang inti (Gambar 7a). Daya dukung ruang inti dilihat dari jarak jarak sosial dengan rentang 1,2 m sampai 2,1m (Hall, 1966). Dilihat dari luas ruang inti sebesar $2.500 \mathrm{~m}^{2}$, maka rentang daya dukung pada ruang tersebut yaitu 1.222 orang pada jarak 1,2 m dan 396 orang pada jarak 2,1 m, maka ruang inti mampu menampung pengunjung dengan persentase sebesar $13 \%$ dari total keseluruhan jumlah anak dalam kondisi nyaman.

Ruang penyangga berfungsi sebagai penyangga yang memberikan keamanan dan kenyamanan bagi pengguna ruang inti, sekaligus sebagai ruang yang membatas tapak bermain dengan lingkungan luarnya (Hersanti, 2002). Pada ruang penyangga ruang yang dikembangkan bagi klaster usia $6-18$ tahun (kanakkanak sampai remaja awal). Pada ruang penyangga lebih ke aktivitas aktif dengan berbagai fasilitas fisik yang dikembangkan pada ruang penyangga yaitu lapangan sepak bola, lapangan basket, jogging track, gym outdoor, jalur sepeda, jalan setapak, batu refleksi, entrance dan gazebo (Gambar 7b), lahan rumput, lampu taman, tempat sampah, tanaman peneduh dan tanaman pembatas fisik. Selain sebagai pengangga, beberapa aktivitas dapat dilakukan seperti bermain sepak bola, bermain basket, jogging, dan berjalan-jalan dengan penerapan tanaman fungsi pembatas fisik dan pengendali iklim mikro (Gambar 8b). Dilihat dari luas ruang penyangga sebesar $11.000 \mathrm{~m}^{2}$, maka rentang daya dukung pada ruang tersebut yaitu 2.444 orang pada jarak 1,2 $\mathrm{m}$ dan 793 orang pada jarak 2,1 m, maka ruang penyangga mampu menampung pengunjung dengan persentase sebesar $58 \%$ dari total keseluruhan jumlah anak dalam kondisi nyaman.

Ruang luar merupakan zona pertama yang dimasuki oleh pengguna tapak. Adapun fasilitas fisik yang dikembangkan pada ruang luar yaitu tempat parkir kendaraan (Gambar 7e), pintu gerbang (entrance), signage, balai, gazebo, jalur pedestrian, lampu taman, tempat pembuangan sampah sementara, tanaman pembatas fisik dan peneduh. Pada welcome area terdapat fasilitas akses bagi pengunjung jalan kaki, jalur sepeda, kendaraan mobil dan seperda motor dengan penerapan tanaman fungsi pembatas fisik dan pengendali iklim mikro (Gambar 8c). Dilihat dari luas ruang luar sebesar $5.500 \mathrm{~m}^{2}$, maka rentang daya dukung pada ruang 
tersebut yaitu 1.222 orang pada jarak 1,2 m dan 396 orang pada jarak 2,1 m, maka ruang luar mampu menampung pengunjung dengan persentase sebesar $29 \%$ dari total keseluruhan jumlah anak dalam kondisi nyaman.

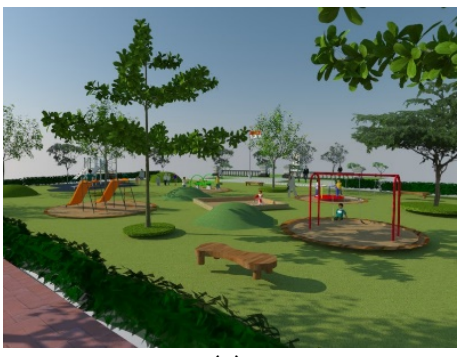

(a)

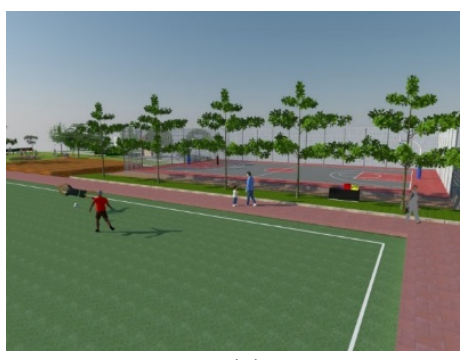

(b)

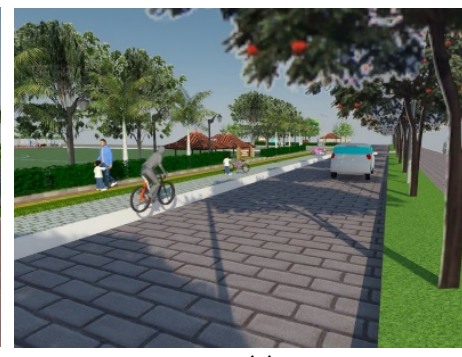

(c)

Gambar 8. Ilustrasi Rencana RTPLA di Lapangan Astina Jaya Blahbatuh Keterangan: $a=$ Ruang Inti, $b=$ Ruang Penyangga,$c=$ Ruang Luar

\section{Simpulan dan Saran \\ 4.1 Simpulan}

Kawasan Lapangan Astina Jaya merupakan ruang terbuka publik desa untuk memfasilitasi penduduk sebagai aktivitas di luar ruangan. Terdapat berbagai klaster pengguna Lapangan Astina Jaya mulai dari anak hingga dewasa awal. Kendala yang terdapat pada kawasan Lapangan Astina Jaya antara lain minimnya fasilitas khususnya bagi anak dalam beraktivitas di luar ruangan, keadaan minimnya partisipasi pengguna anak pada tapak, serta keadaan tapak yang kurang tertata dan terawat. Adapun potensi tapak dalam pengembangannya sebagai ruang terbuka publik layak anak yakni lokasi yang strategis dan memiliki luas yang cukup untuk dikembangkan dalam pemenuhan kebutuhan anak melalui pemanfaatan waktu luang, kegiatan rekreasi, dan pendidikan. Kawasan Lapangan Astina Jaya mampu menampung pengunjung 4.222 orang dari total luas tapak sebesar $19.000 \mathrm{~m}^{2}$ dengan kriteria jarak sosial 1,2 sampai 2,1 m, sehingga jumlah keseluruhan anak pada Desa Blahbatuh sebesar 2.544 dapat tertampung dan memberi rasa nyaman dalam berinteraksi.

Konsep dasar pada perencanaan ini yaitu ruang terbuka publik layak anak dalam bentuk taman lingkungan untuk umum khususnya anak dalam batas usia 3-18 tahun yang dapat menjadi sarana rekreasi yang atraktif dan edukatif yang bertujuan untuk menstimulasi beragam kecerdasan anak di lingkungan tempat tinggal. Konsep pengembangan ruang meliputi ruang inti, ruang penyangga, dan ruang luar. Konsep permainan anak meliputi permainan fisik, permainan sosial, dan permainan kreatif. Konsep edukasi melalui pengembangan area tugu pahlawan, penerapan tanaman obat dan buah. Konsep sirkulasi membagi sirkulasi antara sirkulasi primer dan sekunder, serta konsep vegetasi yang dikembangkan memiliki fungsi pembatas fisik, fungsi pengendali iklim dan fungsi edukasi. Hasil akhir berupa gambar dalam bentuk site plan.

\subsection{Saran}

Rekomendasi penelitian ini diharapkan dapat menjadi masukan bahan pengembangan dalam merencanakan ruang terbuka publik layak anak dan hasil penelitian ini dapat dilanjutkan bagi peneliti mengenai desain taman lingkungan yang ramah anak dengan memperhatikan aspek estetis, aspek sosial, dan detail fasilitas bagi pengunjung khususnya anak untuk beraktivitas di luar ruangan.

\section{Daftar Pustaka}

BLH Kab. Gianyar. 2016. Kondisi Geografis (online). (diunduh pada Juli 2017). Tersedia dalam jaringan pada: http://blh-gianyarkab.info/index.php/kondisi-lingkungan/kondisi-geografis.

BPS Kab. Gianyar. 2016. Statistik Daerah Kecamatan Sukawati 2016. Gianyar: Badan Pusat Statistik Kabupaten Gianyar. $66 \mathrm{hlm}$.

Budyatna, M. dan Ganiem, L.M. (2011). Teori Komunikasi Antarpribadi. Jakarta: Kencana.

Hakim, R. dan H. Utomo. 2008. Komponen Perancangan Arsitektur Lansekap: Prinsip-Unsur dan Aplikasi Desain. Bumi Aksara. Jakarta. $126 \mathrm{hlm}$. 
Hall, E. T. (1966). The Hidden Dimension. Anchor Books. ISBN 0-385-08476-5. 201 p.

Hersanti,I. 2002. Perencanaan Taman Bermain dan Jalur Hijau Jalan di Kluster Taman Victoria - Permukiman Bukit Sentul, Citeureup, Bogor. Skripsi S1. Institut Pertanian Bogor.

Peraturan Kementerian Negara Pemberdayaan Perempuan dan Perlindungan Anak Republik Indonesia No.14 Tahun 2010 Tentang Petunjuk Teknis Kabupaten/Kota Layak Anak di Desa/Kelurahan. Jakarta. 20 hIm.

Peraturan Kementerian Pekerjaan Umum. 2008. Pedoman Penyediaan dan Pemanfaatan Ruang Terbuka Hijau di Kawasan Perkotaan. Direktorat Jendral Penataan Ruang Departemen Pekerjaan Umum: Jakarta.

Portal Resmi Badan Lingkungan Hidup Kabupaten Gianyar. 2016. Kondisi Geografis (online). (diunduh pada Juli 2017). Tersedia dalam jaringan pada: http://blh-gianyarkab.info/index.php/kondisilingkungan/kondisi-geografis.

Simonds, J.O., dan B.W. Starke. 2006. Landscape Architecture: A Manual of Environmental Planning and Design. McGraw-Hill Book Co. New York. 396 p.

Wikipedia, 2017. Bodhi (pohon) (online). (diunduh pada Juli 2017). Tersedia dalam jaringan pada: https://id.wikipedia.org/wiki/Bodhi_(pohon) 